\title{
Model Order Reduction of Interval Systems using Mihailov Criterion and Factor Division Method
}

\author{
D. Kranthi Kumar \\ Research Scholar \\ Dept.of Electrical \\ Engineering \\ Institute of Technology \\ Banaras Hindu University, \\ Varanasi, 221005, UP, India.
}

\author{
S. K. Nagar \\ Professor \\ Dept.of Electrical \\ Engineering \\ Institute of Technology \\ Banaras Hindu University, \\ Varanasi, 221005, UP, India.
}

\author{
J. P. Tiwari \\ Professor \\ Dept.of Electrical \\ Engineering \\ Institute of Technology \\ Banaras Hindu University, \\ Varanasi, 221005, UP, India.
}

\begin{abstract}
This paper presents a mixed method for reducing order of the large scale interval systems using the Mihailov Criterion and factor division method. The denominator coefficients of reduced order model is determined by using Mihailov Criterion and numerator coefficients are obtained by using Factor division method. The mixed methods are simple and guarantee the stability of the reduced model if the original system is stable. Numerical examples are discussed to illustrate the usefulness of the proposed method.
\end{abstract}

\section{Keywords}

Factor division, Mihailov Criterion, Mixed method, Reduced order, Stability.

\section{INTRODUCTION}

The analysis of high order systems is both tedious and costly as high order systems are often too complicated to be used in real problems. Using mathematical approaches are generally employed to realize simple models for the original high order systems. Reducing a high order system into its lower order system is considered important in analysis, synthesis and simulation of practical systems. Numerical methods are available in the literature for order reduction of large scale systems002E

Some of the important methods are method of aggregation [1] the method is derived by "aggregating" the original system state vector. Using Aggregation method some properties are explained briefly. An algorithm was introduced for reduced order model using Pade approximation [2], Routh approximation [3] has done by using $\alpha$ and $\beta$ table and Routh stability for model reduction [4], [3-4] is considered as a Stability based model reduction, moment matching technique [5], Optimal hankel norm approximation [6], Factor division method [7] . Using Pade approximation techniques has many advantages such as computational simplicity. There is a serious disadvantage by using Pade approximation, it gives unstable reduced model, even though original system is stable.

So to neglect these problems mixed methods [8-9] are introduced. Many researchers have attracted the attention on interval systems and to study the stability and the transient analysis of interval systems [10-11]. For reduction of continuous interval systems Routh approximation has been proposed [12], $\gamma-\delta$ Routh approximation has been proposed for model order reduction of interval systems [13], to reduce the complexity of calculations a simple direct method using only $\gamma$ table [14] has been proposed.

In this paper is carried model order reduction of interval systems by using mixed method. The denominator of the interval reduced model is obtained by Mihailov Criterion and the numerator is obtained by Factor division method. Thus the stability of the reduced order model of interval system is guaranteed if the higher order interval system is asymptotically stable. The outline of this paper is as follows: Section 2 contains problem statement. Section 3 contains proposed method and Integral square error is presented in section 4. Numerical example is presented in section 5 and the conclusion in section 6.

\section{PROBLEM STATEMENT}

Let the transfer function of a higher order interval systems be

$$
G_{n}(s)=\frac{\left[p_{0}^{-}, p_{0}^{+}\right]+\left[p_{1}^{-}, p_{1}^{+}\right] s+\ldots \ldots+\left[p_{n-1}^{-}, p_{n-1}^{+}\right] s^{n-1}}{\left[q_{0}^{-}, q_{0}^{+}\right]+\left[q_{1}^{-}, q_{1}^{+}\right] s+\ldots \ldots .+\left[q_{n}^{-}, q_{n}^{+}\right] s^{n}}=\frac{N(s)}{D(s)}
$$

where $\left[p_{i}^{-}, p_{i}^{+}\right]$for $\mathrm{i}=0$ to $\mathrm{n}-1$ and $\left[q_{i}^{-}, q_{i}^{+}\right]$for $\mathrm{i}=0$ to $\mathrm{n}$ are known as scalar constants.

The reduced order model of a transfer function be considered as

$$
R_{r}(s)=\frac{\left[u_{0}^{-}, u_{0}^{+}\right]+\left[u_{1}^{-}, u_{1}^{+}\right] s+\ldots \ldots+\left[u_{r-1}^{-}, u_{r-1}^{+}\right] s^{r-1}}{\left[v_{0}^{-}, v_{0}^{+}\right]+\left[v_{1}^{-}, v_{1}^{+}\right] s+\ldots \ldots+\left[v_{r}^{-}, v_{r}^{+}\right] s^{r}}=\frac{N_{r}(s)}{D_{r}(s)}
$$

where $\left[u_{j}^{-}, u_{j}^{+}\right]$for $\mathrm{j}=0$ to $\mathrm{r}-1$ and $\left[v_{j}^{-}, v_{j}^{+}\right]$for $\mathrm{j}=0$ to $\mathrm{r}$ are known as scalar constants.

The rules of the interval arithmetic have been defined in [15], as follows.

Let $[\mathrm{e}, \mathrm{f}]$ and $[\mathrm{g}, \mathrm{h}]$ be two intervals.

Addition:

$$
[e, f]+[g, h]=[e+g, f+h]
$$

Subtraction:

$$
[e, f]-[g, h]=[e-h, f-g]
$$


Multiplication:

$[e, f][g, h]=[\operatorname{Min}(e g, e h, f g, f h), \operatorname{Max}(e g, e h, f g, f h)]$

Division:

$$
\frac{[e, f]}{[g, h]}=[e, f]\left[\frac{1}{h}, \frac{1}{g}\right]
$$

\section{PROPOSED METHOD}

The proposed method consists of the following steps for obtaining reduced order model.

Step1: Determination of the denominator polynomial of the $r^{\text {th }}$ order reduced model by Mihailov Criterion

Substituting $s=j \omega$ in $D(s)$ and separating the denominator into real and imaginary parts

$$
\begin{aligned}
& D(j \omega)=\left[q_{0}^{-}, q_{0}^{+}\right]+\left[q_{1}^{-}, q_{1}^{+}\right](j \omega)+\ldots .+\left[q_{1, n}^{-}, q_{1, n}^{+}\right](j \omega)^{n} \\
& =\left(\left[q_{0}^{-}, q_{0}^{+}\right]-\left[q_{2}^{-}, q_{2}^{+}\right] \omega^{2}+\ldots \ldots\right)+ \\
& \quad j \omega\left(\left[q_{1}^{-}, q_{1}^{+}\right]-\left[q_{3}^{-}, q_{3}^{+}\right] \omega^{2}+\ldots \ldots\right) \\
& =\xi(\omega)+j \omega \psi(\omega)
\end{aligned}
$$

where $\omega$ is the angular frequency, $\mathrm{rad} / \mathrm{sec}$.

$\xi(\omega)=0$ and $\psi(\omega)=0$, the frequencies which are intersecting $\omega_{0}=0, \pm\left[\omega_{1}^{-}, \omega_{1}^{+}\right], \ldots \ldots \pm\left[\omega_{n-1}^{-}, \omega_{n-1}^{+}\right]$are obtained, where $\left|\left[\omega_{1}^{-}, \omega_{1}^{+}\right]\right| \prec\left|\left[\omega_{2}^{-}, \omega_{2}^{+}\right]\right|<\ldots . .<\left|\left[\omega_{n-1}^{-}, \omega_{n-1}^{+}\right]\right|$.

Similarly substituting $\mathrm{s}=\mathrm{j} \omega$ in $D_{r}(s)$, then obtains

$$
D_{r}(j \omega)=\phi(\omega)+j \omega \psi(\omega)
$$

where

$$
\begin{aligned}
& \phi(\omega)=\left[v_{0}^{-}, v_{0}^{+}\right]-\left[v_{2}^{-}, v_{2}^{+}\right] \omega^{2}+\ldots \text { and } \\
& \psi(\omega)=\left[v_{1}^{-}, v_{1}^{+}\right]-\left[v_{3}^{-}, v_{3}^{+}\right] \omega^{2}+\ldots
\end{aligned}
$$

Putting $\phi(\omega)=0$ and $\psi(\omega)=0$, then we get ' $r$ ' number of roots and it must be positive and real and alternately distributed along the $\omega$ axis. The first ' $r$ ' numbers of frequencies are $0,\left[\omega_{1}^{-}, \omega_{1}^{+}\right]$, $\left[\omega_{2}^{-}, \omega_{2}^{+}\right], \ldots \ldots\left[\omega_{r-1}^{-}, \omega_{r-1}^{+}\right]$are kept unchanged and the roots of $\phi(\omega)=0$ and $\psi(\omega)=0$.

Therefore,

$\phi(\omega)=$

$\left[\lambda_{1}^{-}, \lambda_{1}^{+}\right]\left(\omega^{2}-\left[\omega_{1}^{-2}, \omega_{1}^{+2}\right]\right)\left(\omega^{2}-\left[\omega_{3}^{-2}, \omega_{3}^{+2}\right]\right) \ldots \ldots$

$\psi(\omega)=\left[\lambda_{2}^{-}, \lambda_{2}^{+}\right]\left(\omega^{2}-\left[\omega_{2}^{-2}, \omega_{2}^{+2}\right]\right)\left(\omega^{2}-\left[\omega_{4}^{-2}, \omega_{4}^{+2}\right]\right)$.

For finding the coefficient values of $\left[\lambda_{1}^{-}, \lambda_{1}^{+}\right]$and $\left[\lambda_{2}^{-}, \lambda_{2}^{+}\right]$are calculated from $\xi(0) \quad \phi(0)$ and $\square\left(\left[\omega_{1}^{-}, \omega_{1}^{+}\right]\right)=\psi\left(\left[\omega_{1}^{-}, \omega_{1}^{+}\right]\right)$. keeping these values of $\left[\lambda_{1}^{-}, \lambda_{1}^{+}\right]$and $\left[\lambda_{2}^{-}, \lambda_{2}^{+}\right]$in equations (5) and (6), respectively, $\phi$ $(\omega)$ and $\psi(\omega)$ are obtained and $D_{k}(j \omega)$ is obtained as

$$
D_{r}(j \omega)=\boldsymbol{\phi}(\omega)+j \omega \boldsymbol{\psi}(\omega)
$$

Now replace j $\omega$ by s and then the $r^{\text {th }}$ order reduced denominator $D_{r}(s)$ is obtained as

$D_{r}(s)=\left[v_{0}^{-}, v_{0}^{+}\right]+\left[v_{1}^{-}, v_{1}^{+}\right] s+\ldots \ldots+\left[v_{r}^{-}, v_{r}^{+}\right] s^{r}$

Step 2: Determination of the numerator coefficients of the $r^{\text {th }}$ order reduced model by using factor division method:

Any method of reduction which relies upon calculating the reduced denominator first and then the numerator, where $D_{r}(s)$ has already been calculated.

$G(s)=\frac{N(s) D_{r}(s) / D(s)}{D(s)}$

$\frac{N(s) D_{r}(s)}{D(s)}=\left[u_{0}^{-}, u_{0}^{+}\right]+\left[u_{1}^{-}, u_{1}^{+}\right] s+\cdots+\left[u_{r-1}^{-}, u_{r-1}^{+}\right] s^{r-1}$

$\frac{N(s) D_{r}(s) / D(s)}{D(s)}=\frac{\left[u_{0}^{-}, u_{0}^{+}\right]+\left[u_{1}^{-}, u_{1}^{+}\right] s+\cdots+\left[u_{r-1}^{-}, u_{r-1}^{+}\right] s^{r-1}}{\left[v_{0}^{-}, v_{0}^{+}\right]+\left[v_{1}^{-}, v_{1}^{+}\right] s+\ldots+\left[v_{r}^{-}, v_{r}^{+}\right] s^{r}}$

Therefore,

$$
\begin{gathered}
{\left[\alpha_{0}^{-}, \alpha_{0}^{+}\right]=\frac{\left[u_{0}^{-}, u_{0}^{+}\right]}{\left[v_{0}^{-}, v_{0}^{+}\right]} \begin{cases}{\left[u_{0}^{-}, u_{0}^{+}\right]\left[u_{1}^{-}, u_{1}^{+}\right]} & \ldots \ldots \\
{\left[v_{0}^{-}, v_{0}^{+}\right]\left[v_{1}^{-}, v_{1}^{+}\right]} & \ldots \ldots\end{cases} } \\
{\left[\alpha_{1}^{-}, \alpha_{1}^{+}\right]=\frac{\left[r_{0}^{-}, r_{0}^{+}\right]}{\left[v_{0}^{-}, v_{0}^{+}\right]} \begin{cases}{\left[r_{0}^{-}, r_{0}^{+}\right]\left[r_{1}^{-}, r_{1}^{+}\right]} & \ldots \ldots \\
{\left[v_{0}^{-}, v_{0}^{+}\right]\left[v_{1}^{-}, v_{1}^{+}\right]} & \ldots \ldots\end{cases} } \\
{\left[\alpha_{2}^{-}, \alpha_{2}^{+}\right]=\frac{\left[s_{0}^{-}, s_{0}^{+}\right]}{\left[v_{0}^{-}, v_{0}^{+}\right]} \begin{cases}{\left[s_{0}^{-}, s_{0}^{+}\right]\left[s_{1}^{-}, s_{1}^{+}\right]} & \ldots \ldots \\
{\left[v_{0}^{-}, v_{0}^{+}\right]\left[v_{1}^{-}, v_{1}^{+}\right]} & \ldots \ldots\end{cases} }
\end{gathered}
$$

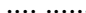

$$
\begin{gathered}
{\left[\alpha_{r-2}^{-}, \alpha_{r-2}^{+}\right]=\frac{\left[x_{0}^{-}, x_{0}^{+}\right]}{\left[v_{0}^{-}, v_{0}^{+}\right]}\left\{\begin{array}{l}
{\left[x_{0}^{-}, x_{0}^{+}\right]\left[x_{1}^{-}, x_{1}^{+}\right]} \\
{\left[v_{0}^{-}, v_{0}^{+}\right]\left[v_{1}^{-}, v_{1}^{+}\right]}
\end{array}\right.} \\
{\left[\alpha_{r-1}^{-}, \alpha_{r-1}^{+}\right]=\frac{\left[y_{0}^{-}, y_{0}^{+}\right]}{\left[v_{0}^{-}, v_{0}^{+}\right]}\left\{\begin{array}{l}
{\left[y_{0}^{-}, y_{0}^{+}\right]} \\
{\left[v_{0}^{-}, v_{0}^{+}\right]}
\end{array}\right.}
\end{gathered}
$$

where

$\left[r_{i}^{-}, r_{i}^{+}\right]=\left[u_{i+1}^{-}, u_{i+1}^{+}\right]-\left[\alpha_{0}^{-}, \alpha_{0}^{+}\right]\left[v_{i+1}^{-}, v_{i+1}^{+}\right] ; \mathrm{i}=0,1, . \mathrm{r}-2$

$\left[s_{i}^{-}, s_{i}^{+}\right]=\left[u_{i+1}^{-}, u_{i+1}^{+}\right]-\left[\alpha_{1}^{-}, \alpha_{1}^{+}\right]\left[v_{i+1}^{-}, v_{i+1}^{+}\right] ; \quad \mathrm{i}=0,1, \ldots \mathrm{r}-3$

$$
\left[y_{i}^{-}, y_{i}^{+}\right]=\left[x_{1}^{-}, x_{1}^{+}\right]-\left[\alpha_{k-2}^{-}, \alpha_{k-2}^{+}\right]\left[v_{1}^{-}, v_{1}^{+}\right]
$$

The reduced transfer function given by

$$
R_{k}(s)=\frac{\left[\alpha_{0}^{-}, \alpha_{0}^{+}\right]+\left[\alpha_{1}^{-}, \alpha_{1}^{+}\right] s+\ldots .+\left[\alpha_{r-1}^{-}, \alpha_{r-1}^{+}\right] s^{r-1}}{D_{r}(s)}
$$




\section{INTEGRAL SQUARE ERROR}

The integral square error (ISE) between the transient responses of higher order system (HOS) and Lower order system (LOS) is given by:

$$
\mathrm{ISE}=\int_{0}^{\infty}\left[y(t)-y_{r}(t)\right]^{2}
$$

where, $y(t)$ and $y_{r}(\mathrm{t})$ are the unit step responses of original system $G_{n}(s)$ and reduced order system $R_{k}(s)$.

\section{NUMERICAL EXAMPLE}

Example 1: Consider a third order system described by the transfer function [13]

$$
G_{3}(s)=\frac{[2,3] s^{2}+[17.5,18.5] s+[15,16]}{[2,3] s^{3}+[17,18] s^{2}+[35,36] s+[20.5,21.5]}
$$

Step 1: Put $s=j \omega$ in the denominator D (s)

$D(j \omega)=\left([20.5,21.5]-[17,18] \omega^{2}\right)+j \omega\left([35,36]-[2,3] \omega^{2}\right)$

Step 2: The intersecting frequencies are

$\left[\omega_{i}^{-}, \omega_{i}^{+}\right]=0,[1.0929,1.0981],[3.4641,4.1833]$

Step 3: The denominator of the second order model is taken as

$D_{2}(j \omega)=\left[\lambda_{1}^{-}, \lambda_{1}^{+}\right]\left(\omega^{2}-[1.0929,1.9081]^{2}\right)+$ $j \omega\left[\lambda_{2}^{-}, \lambda_{2}^{+}\right]$.

Here $\left[\lambda_{1}^{-}, \lambda_{1}^{+}\right]=-[17.0011,18.0007]$ and $\left[\lambda_{2}^{-}, \lambda_{2}^{+}\right]=$ $[31.3826,33.6111]$

Step 4: Substitute the values of $\left[\lambda_{1}^{-}, \lambda_{1}^{+}\right]$and $\left[\lambda_{2}^{-}, \lambda_{2}^{+}\right]$in step 3 and also substitute $j \omega=s$.

Hence, the denominator $\mathrm{D}(\mathrm{s})$ is given by

$$
\begin{gathered}
D_{2}(s)=[17.0011,18.0007] s^{2}+[31.3826,33.6111] s \\
+[20.3061,21.7052]
\end{gathered}
$$

Step5: Using the factor division method

$$
\begin{aligned}
& \frac{N(s) D_{r}(s) / D(s)}{D(s)} \\
& =\frac{[304.5915,347.2832]+[826.0957,939.3238] s+\ldots \ldots \ldots}{[20.3061,21.7052]+[31.3826,33.6111] s+\ldots \ldots \ldots}
\end{aligned}
$$

Step 6: Finding the values of $\left[\alpha_{0}^{-}, \alpha_{0}^{+}\right]$and $\left[\alpha_{1}^{-}, \alpha_{1}^{+}\right]$

$$
\left[\alpha_{0}^{-}, \alpha_{0}^{+}\right]=[14.0331,17.1024]
$$

$\left[\alpha_{1}^{-}, \alpha_{1}^{+}\right]=[35.6065,49.4454]$

$N_{r}(s)=[14.0331,17.1024]+[35.6065,49.4454] s$

Step7: The reduced transfer function is

$$
\begin{aligned}
& R_{r}(s) \\
& =\frac{[35.6065,49.4454] s+[14.0331,17.1024]}{[17.0011,18.0007] s^{2}+[31.3826,33.6111] s+[20.3061,21.7052]}
\end{aligned}
$$

The step response of second order model is obtained by the proposed method is shown in Fig 1. The comparison of ISE for lower limit and upper limit are shown in Table 1.

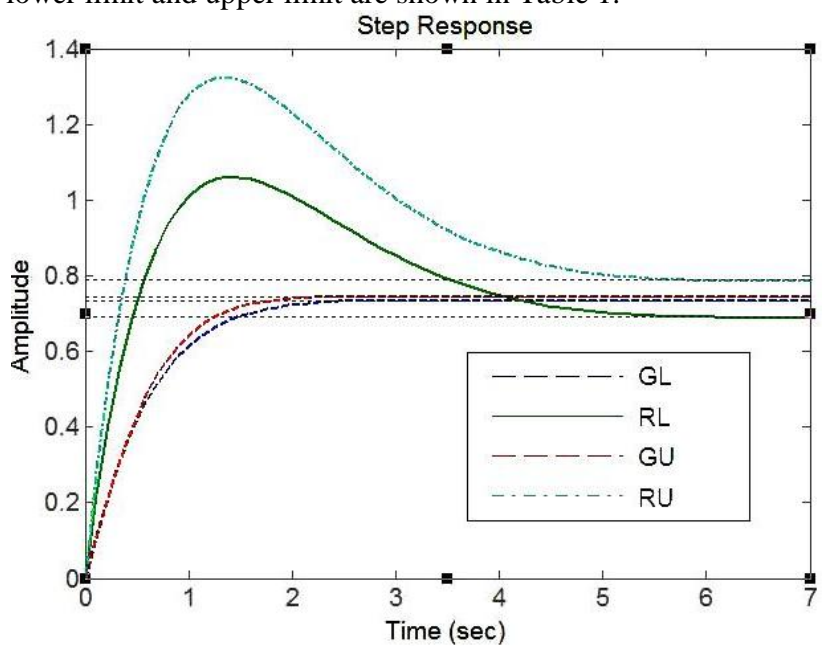

Fig. 1: Step Response of original model and reduced model using Mihailov Criterion and Factor division

Table 1. Comparison of Reduced Order Models

\begin{tabular}{|l|c|l|}
\hline Method of Order reduction & $\begin{array}{l}\text { ISE for lower } \\
\text { limit errL }\end{array}$ & $\begin{array}{l}\text { ISE for upper } \\
\text { limit err }\end{array}$ \\
\hline $\begin{array}{l}\text { Mihailov Criterion and } \\
\text { Factor division }\end{array}$ & 0.0124 & 0.0169 \\
\hline $\begin{array}{l}\text { Sastry, G.V.K. et.al } \\
(2000)\end{array}$ & 0.2256 & 0.0095 \\
\hline
\end{tabular}

Example 2: Consider a third order system described by the transfer function [13]

$$
G_{3}(s)=\frac{[3,4] s^{2}+[25,26] s+[14,15]}{[7,8] s^{3}+[54,55] s^{2}+[90,91] s+[35,36]}
$$

Step 1: Put $s=j \omega$ in the denominator D (s)

$$
D(j \omega)=\left([35,36]-[54,55] \omega^{2}\right)+j \omega\left([90,91]-[7,8] \omega^{2}\right)
$$

Step 2: The intersecting frequencies are

$$
\left[\omega_{i}^{-}, \omega_{i}^{+}\right]=0,[0.8051,0.8090],[3.3726,3.5857]
$$

Step 3: The denominator of the second order model is taken as

$$
D_{2}(j \omega)=\left[\lambda_{1}^{-}, \lambda_{1}^{+}\right]\left(\omega^{2}-[0.8051,0.8090]^{2}\right)+
$$
$j \omega\left[\lambda_{2}^{-}, \lambda_{2}^{+}\right]$.

Here $\left[\lambda_{1}^{-}, \lambda_{1}^{+}\right]=-[53.4759,55.5384]$ and $\left[\lambda_{2}^{-}, \lambda_{2}^{+}\right]=$ $[85.4626,85.764]$ 
Step 4: Substitute the values of $\left[\lambda_{1}^{-}, \lambda_{1}^{+}\right]$and $\left[\lambda_{2}^{-}, \lambda_{2}^{+}\right]$in step 3 and also substitute $j \omega=$ s.

Hence, the denominator $\mathrm{D}(\mathrm{s})$ is given by

$$
\begin{gathered}
D_{2}(s)=[53.4759,55.5384] s^{2}+[85.4626,85.764] s \\
+[34.6631,36.3499]
\end{gathered}
$$

Step5: Using the factor division method

$$
\begin{aligned}
& \frac{N(s) D_{r}(s) / D(s)}{D(s)} \\
& =\frac{[485.2383,545.2485]+[2063.0539,2231.5574] s+\ldots \ldots \ldots}{[35,36]+[90,91] s+\ldots \ldots \ldots}
\end{aligned}
$$

Step 6: Finding the values of $\left[\alpha_{0}^{-}, \alpha_{0}^{+}\right]$and $\left[\alpha_{1}^{-}, \alpha_{1}^{+}\right]$

$$
\left[\alpha_{0}^{-}, \alpha_{0}^{+}\right]=[13.4788,15.5785]
$$

$\left[\alpha_{1}^{-}, \alpha_{1}^{+}\right]=[17.43,29.9303]$

$N_{r}(s)=[13.4788,15.5785]+[17.43,29.9303] s$

Step7: The reduced transfer function is

$$
\begin{aligned}
& R_{r}(s) \\
& =\frac{[17.43,29.9303] s+[13.4788,15.5785]}{[53.4759,55.5384] s^{2}+[85.4626,85.764] s+[34.6631,36.3499]}
\end{aligned}
$$

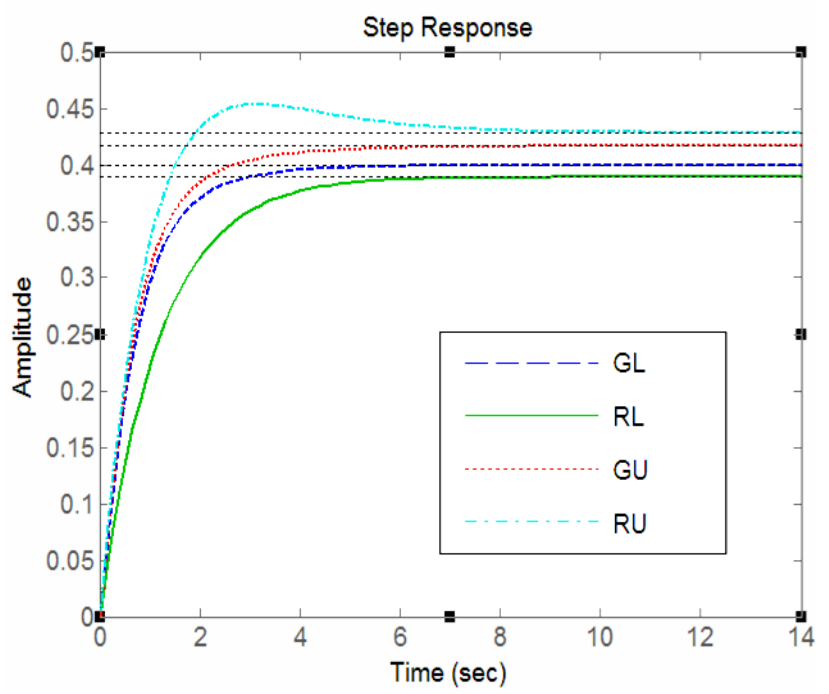

Fig. 2: Step Response of original model and reduced model using Mihailov Criterion and Factor division

The step response of second order model is obtained by the proposed method is shown in Fig 2. The comparison of ISE for lower limit and upper limit are shown in Table 2.
Table 2. Comparison of Reduced Order Models

\begin{tabular}{|l|l|l|}
\hline Method of Order reduction & $\begin{array}{l}\text { ISE for lower } \\
\text { limit errL }\end{array}$ & $\begin{array}{c}\text { ISE for } \\
\text { upper limit } \\
\text { errU }\end{array}$ \\
\hline $\begin{array}{l}\text { Mihailov Criterion and Factor } \\
\text { division }\end{array}$ & $4.3584 \mathrm{e}-004$ & 0.0011 \\
\hline O.Ismail.et.al [16] & $5.2406 \mathrm{e}-004$ & $6.5383 \mathrm{e}-004$ \\
\hline
\end{tabular}

\section{CONCLUSIONS}

In this paper Mihailov Criterion and Factor division method are employed for order reduction. The denominator polynomial of reduced model is obtained by using Mihailov Criterion and the numerator is determined by Factor division method. The proposed method guarantees the stability of reduced model if the original system is stable. These proposed methods are conceptually simple and comparable with other available methods. As illustrated for examples are taken from the literature and compared with other methods by using ISE.

\section{REFERENCES}

[1] M. Aoki, "Control of large-scale dynamic systems by aggregation," IEEE Trans. Automat. Contr., vol. AC-13, pp. 246-253, 1968.

[2] Y. Shamash, "Stable reduced order models using Pade type approximation," IEEE Trans. Automat. Contr., vol. AC-19, pp. 615-616, 1974.

[3] M. F. Hutton and B. Friedland. "Routh approximation for reducing order of linear time invariant system," IEEE Trans. Automat. Contr., vol. AC-20, pp. 329-337, 1975.

[4] V. Krishnamurthy and V. Seshadri, "Model reduction using Routh stability criterion," IEEE Trans. Automat. Contr., vol. AC-23, pp. 729-730, 1978.

[5] N. K. Sinha and B. Kuszta, "Modelling and Identification of Dynamic Systems".

[6] K. Glover, "All optimal Hankel-norm approximations of linear multivariable systems and their Loo error bounds," Int. J. Contr., vol. 39, no. 6, pp. 1115-1193, 1984.

[7] T. N. Lucas. "Factor division - A useful algorithm in model reduction, IEE Proc, Vol. 130, pp.362-364, 1983.

[8] Y. Shamash, "Model reduction using Routh stability criterion and the Pade approximation," Int. J. Contr., vol. 21, pp. 475-484, 1975.

[9] Wan Bai-Wu, " Linear Model reduction using Mihailov Criterion and pade Approximation Technique," International Journal of Control, vol 33, no. 6, pp. 1073, 1981.

[10] V. L. Kharitonov, "Asymptotic stability of an equilibrium position of a family of systems of linear differential equations," Differentsial'nye Uravneniya, vol. 14, pp. 2086-2088, 1978. 
[11] S. P. Bhattacharyya, Robust Stabilization Against Structured Perturbations (Lecture Notes In Control and Information Sciences). New York: Springer-Verlag. 1987.

[12] B. Bandyopadhyay, O. Ismail, and R. Gorez, "Routh Pade approximation for interval systems," IEEE Trans. Automat. Contr., pp. 2454-2456, Dec1994.

[13] B. Bandyopadhyay.: " $\gamma-\delta$ Routh approximations for interval systems," IEEE Trans. Autom. Control, pp. 11271130, 1997.

[14] G V K Sastry, G R Raja Rao and P M Rao, "Large Scale Interval System Modelling Using Routh Approximants," Electronics Letters, vol 36, no 8, pp. 768. April 2000.

[15] E. Hansen, "Interval arithmetic in matrix computations, Part I," SIAM J. Numerical Anal., pp. 308-320, 1965.

[16] O.Ismail and B.Bandyopadhyay, "Model reduction of Linear interval systems using Pade approximation, IEEE International Symposium on Circuits and Systems, vol.2, pp.1400-1403,1995.

\section{AUTHORS BIOGRAPHY}

D. Kranthi Kumar was born in Guntur, A.P, India in 1986. He received the degree of B.E from SIR. C. R. Reddy College of Engineering in 2008 and received the degree of M.Tech in
Electrical Engineering from IT-BHU, Varanasi, in 2010 and presently pursuing Ph.D in Electrical Engineering at IT-BHU, Varanasi, India. He is life member in System Society of India (SSI) and student member in Institute of Engineers (Ireland).

S. K. Nagar was born in Varanasi, India in 1955 . He received the degrees of B.Tech and M.Tech from the Institute of Technology, Banaras Hindu University (IT-BHU), Varanasi, India In 1976 and 1978; and PhD in Electrical Engineering from University of Roorkee (IIT Roorkee), India in 1991. He is currently Professor in Electrical Engineering at IT-BHU, Varanasi, India. His main research includes digital control, model order reduction and discrete event systems. He has published many papers in national \& International conferences \& Journals.

J. P. Tiwari was born in Deoria, U.P, India in 1947. He received the degrees of B.E. and M.E. from University of Roorkee, India in 1968 and 1971. Ph.D in Electrical Engineering from Banaras Hindu University, India in 1991. He is currently Professor, Head of the Department in Department of Electrical Engineering at IT-BHU, Varanasi, India. His main research includes Control systems, Robotics, Instrumentation, Control Systems, Adaptive control. He has published many papers in National \& International conferences and journals. 